\title{
Airway inflammation and bronchial microbial patterns in patients with stable chronic obstructive pulmonary disease
}

\author{
N. Soler*, S. Ewig**, A. Torres ${ }^{+}$, X. Filella, J. Gonzalez, A. Zaubet
}

Airway inflammation and bronchial microbial patterns in patients with stable chronic obstructive pulmonary disease. N. Soler, S. Ewig, A. Torres, X. Filella, J. Gonzalez, A. Xaubet. (C) ERS Journals Ltd 1999.

ABSTRACT: The effect of bacterial colonization of the bronchi on the progress of airflow limitation is not well known. Therefore, the pattern of airway inflammation in smokers and patients with stable chronic obstructive pulmonary disease (COPD) and its relation to bronchial microbial colonization was assessed.

Eight nonsmoking and 18 smoking controls as well as 52 patients with COPD (28 mild, 11 moderate and 13 severe) were studied. All subjects were investigated by means of flexible bronchoscopy including protected specimen brush and bronchoalveolar lavage (BAL) sampling. Differential cell counts, cytokine (interleukin (IL)-1 $\beta$, IL-6, IL-8, IL-10 and tumour necrosis factor- $\alpha$ (TNF- $\alpha)$ concentrations and microbial patterns were determined in BAL fluid.

Forced expiratory volume in one second (FEV1) \% of the predicted value was inversely correlated with pack-yrs of cigarette smoking $(r=-0.47, p<0.0001)$, the percentage of neutrophil $(\rho=-0.56, p<0.0001)$ and IL-6 $(\rho=-0.37, p=0.01)$ and IL-8 concentration $(\rho=-0.43, p=0.004)$ in BAL fluid. Accordingly, pk-yrs of cigarette smoking ( $\rho=0.39$, $p=0.01)$ and IL-8 $(\rho=0.69, p<0.0001)$ and TNF $\alpha(\rho=0.4, p<0.005)$ were positively correlated with the percentage of neutrophils in BAL fluid. Smoking controls and COPD patients were mainly colonized in the bronchial tree $(33 \%)$ by community endogenous potentially pathogenic micro-organisms (PPMs). Colonization rates and patterns of PPMs were not affected by severity of airflow obstruction. The presence of PPMs was significantly associated with higher percentages of neutrophils $(33.2 \pm 10.4 \%$ versus $10.1 \pm 3.5 \%, \mathrm{p}=0.02)$ and $\mathrm{TNF}-\alpha$ concentration $\left(29.9 \pm 10.8\right.$ versus $6.3 \pm 2.1 \mathrm{pg} \cdot \mathrm{mL}^{-1}$, $p=0.01$ ) in BAL fluid.

In conclusion, bronchial neutrophilia is a key inflammatory pattern in chronic obstructive pulmonary disease patients. Bronchial colonization with potentially pathogenic micro-organisms may represent an independent stimulus for additional airway inflammation.

Eur Respir J 1999; 14: 1015-1022.
*Hospital Clinic, Barcelona, Spain **Medizinische Universitätsklinik and Poliklinik Bonn, Bonn, Germany ${ }^{+}$Hospital Clinic i Provincial, Servei de Pneumologia i Al.leria Respiratoria, Barcelona, Spain

Correspondence: A. Torres, Hospital Clinic i Provincial, Servei de Pneumologia i Al.leria Respiratoria, Villaroel 17008036 Barcelona, Spain. Fax 34932275454

Keywords: Bronchoalveolar lavage fluid chronic obstructive pulmonary disease (COPD)

colonization

inflammation

Received: February 81999

Accepted after revision July 121999

Supported by Commisionat per a Universitats i Recerca de la Generalitat de Catalunya, 1997 SGR 00086, and IDIBAPS Hospital Clinic Barcelona and GlaxoWellcome.
Bacterial colonization of distal airways with pathogenic as well as nonpathogenic agents is frequently found [1-4]. The significance of bacterial colonization of the bronchial tree in terms of the development and progression of airflow limitation as well as in acute exacerbations is not precisely known. Nevertheless, there is evidence that the acute and chronic inflammatory response to bacterial pathogens is an important contributor to the damage of epithelial surfaces, thus promoting further bronchial colonization, acute infections and impairment of local immune responses [5-8].

Nevertheless, the exact relation between markers of bronchial airway inflammation and smoking behaviour, severity of airway obstruction and microbial patterns of bronchial colonization has not yet been established. Particularly, no study to date has concomitantly assessed inflammatory as well as microbial patterns by means of bronchoscopically retrieved samples in patients with severe chronic obstructive pulmonary disease (COPD).

Therefore, a study was carried out in patients with stable COPD of differing severity, without prior antimicrobial treatment, in order to determine the pattern of bronchial airway inflammation via differential cell count and cytokine patterns found in bronchoalveolar lavage (BAL) fluid and their relationship with microbial patterns of bronchial colonization assessed by the protected specimen brush technique (PSB) and BAL.

\section{Materials and methods}

\section{Patient population}

The study was conducted between January 1996 and March 1997. Stable nonsmoking patients, smoking patients with normal spirometry results, and stable COPD patients with an indication for bronchoscopy were eligible. A stable clinical condition was defined by the absence of symptoms of a lower respiratory tract infection (increase in dyspnoea, cough and/or purulent sputum) for $\geq 3$ months prior to inclusion in the study. Exclusion criteria were: antimicrobial treatment during the last $\geq 4$ weeks, treatment with oral 
corticosteroids during the last 3 months, hospital admission during the last 3 months, evidence of bronchiectasis according to clinical and chest radiography criteria and any severe comorbid conditions such as severe immunosuppression, malignancies, and coagulopathies.

Eight nonsmoking and 18 smoking patients without COPD comprised the control groups, and 52 patients with COPD the case groups. The indications for performing fibreoptic bronchoscopy were: mild haemoptysis $(n=40)$, hilar enlargement $(n=18)$, pulmonary nodules $(n=10)$ and others $(n=10)$. Exploration of the bronchial tree and further evaluation showed no evidence for neoplasia or sarcoidosis in any case.

Smoking controls had a history of cigarette smoking of $\geq 15$ pack-yrs (range $15-80$, mean \pm SD $41 \pm 21$ ). World Health Organization criteria for chronic bronchitis (cough and sputum for $\geq 3$ months during the last 2 yrs) were met by nine (50\%) smoking controls and 28 (54\%) COPD patients. All patients underwent forced spirometry as well as reversibility testing. No patient fulfilled reversibility criteria as defined by the American Thoracic Society (ATS) guidelines [9]. COPD case groups were classified as mild forced expiratory volume in one second (FEV1) $>50 \%$ of the predicted value, $n=28)$, moderate $(50-35 \%, n=11)$, and severe $(<35 \%$ pred, $n=13)$ according to ATS guidelines [9]. No control and no COPD patient had evidence of atopy or asthma. Patients with severe COPD significantly more often had a history of prior acute exacerbations within the last year as compared to patients with mild and moderate COPD $(\mathrm{p}<0.0001)$ (table 1$)$.

\section{Study protocol}

The study protocol was approved by the local ethical committee. Informed written consent was obtained from all patients.

The history of current symptoms, number of prior exacerbations, concomitant morbidities, and current treatment were retrieved by means of a standardized questionnaire.

All patients were subjected to fibreoptic bronchoscopy including the PSB technique and BAL. Flexible bronchoscopy was performed transnasally (BF 30; Olympus, New
Hyde Park, NY, USA). Prior to bronchoscopy, patients received topical anaesthesia by inhalation of nebulized lignocaine $(8 \mathrm{ml}, 4 \%$ solution). No additional anaesthestic was instilled nor was any aspiration performed through the inner channel of the bronchoscope during the procedure. After inspection of the bronchial tree, a PSB (Microbiology brush; Mill-Rose Laboratory Inc., Mentor, OH, USA) sample was obtained from a segmental orifice of the right or left lower lobe. BAL was performed at the same site with $5 \times 30 \mathrm{~mL}$ nonbacteriostatic saline. The first reaspirated portion was discarded. The volume of the remaining recovered BAL fluid was recorded, and then divided into two equal aliquots for cytological examination/cytokine measurements and quantitative bacterial cultures.

\section{Cytological examinations}

The BAL fluid was centrifuged for $10 \mathrm{~min}$ at 500 revolutions per minute (Cytospin II, Shandon). The cellfree supernatants were stored at $-70^{\circ} \mathrm{C}$ until analysed. Cell viability as well as total and differential cell counts were determined as described elsewhere [10].

\section{Cytokine measurements}

The concentrations of the following cytokines in BAL fluid supernatant were determined: (IL)-1 $\beta$, IL-6, IL-8, IL10 , and tumour necrosis factor- $\alpha$ (TNF- $\alpha$ ). A solid phase enzyme-linked immunosorbent assay (ELISA) based on the quantitative immunometric sandwich enzyme immunoassay technique in a microtitre plate (Enzyme Amplified Sensitivity immunoassay (EASIA); Medgenix Diagnostics, Fleurus, Belgium (IL-1 $\beta$, IL- 6 and TNF- $\alpha$ ) and Perseptive, Framingham, MA, USA (IL-8 and IL-10)) was used. This ELISA method used a monoclonal antibody specific to the particular cytokine to be analysed coated on the microtitre plate to create the solid phase. BAL fluid specimens were pipetted into the wells in duplicate. After the cytokine had bound to the immobilized antibody, a second monoclonal antibody was added to the wells and allowed to bind to a different epitope on the same cytokine. In the assays for IL-1 $\beta$, IL6 and TNF- $\alpha$, the monoclonal antibody was conjugated to horseradish peroxidase. In the

Table 1. - Characteristics of controls and patients with chronic obstructive pulmonary disease (COPD)

\begin{tabular}{|c|c|c|c|c|c|}
\hline & \multicolumn{2}{|c|}{ Control } & \multicolumn{3}{|c|}{ COPD } \\
\hline & Nonsmoker & Smoker & Mild & Moderate & Severe \\
\hline Subject n & 8 & 18 & 28 & 11 & 13 \\
\hline Age yrs ** & $51 \pm 11$ & $55 \pm 9$ & $64 \pm 11$ & $66 \pm 10$ & $68 \pm 9$ \\
\hline Sex M/F* & $5 / 3$ & $13 / 5$ & $27 / 1$ & $11 / 0$ & $13 / 0$ \\
\hline \multicolumn{6}{|l|}{ Smoking history } \\
\hline current/past ${ }^{\S}$ & - & $18 / 0$ & $14 / 14$ & 2/9 & $2 / 11$ \\
\hline pack-yrs & - & $41 \pm 21$ & $46 \pm 21$ & $51 \pm 19$ & $60 \pm 17$ \\
\hline FEV1 $\%$ pred*** & $95 \pm 7$ & $94 \pm 10$ & $65 \pm 9$ & $43 \pm 5$ & $28 \pm 6$ \\
\hline Chronic bronchitis & - & $9(50)$ & $13(46)$ & $6(55)$ & $9(69)$ \\
\hline \multicolumn{6}{|c|}{ History of acute exacerbations* } \\
\hline None & - & - & 26 & 7 & 2 \\
\hline 1 & - & - & 1 & 3 & 6 \\
\hline$>1$ & - & - & 1 & 2 & 5 \\
\hline Inhaled steroid treatment & - & & 6 & 6 & 9 \\
\hline
\end{tabular}

Data are presented as mean \pm SD or $n$ with or without percentage in parentheses. ${ }^{\S}$ : smoking cessation $\geq 2$ yrs. The Chi-squared test was used to compare categorical variables and analysis of variance (ANOVA) continuous variables between the two groups, control and COPD. M: male; F: female; FEV1: forced expiratory volume in one second. *: p<0.01 (Chi-squared test); **: p<0.01 (ANOVA); ***: $\mathrm{p}<0.0001$ (ANOVA). 
assays for IL-8 and IL-10, a biotinylated antibody directed against the cytokine was added. Excess antibody was removed by washing and enzyme-conjugated streptavidin, which binds to the sandwich cytokine monoclonal antibody, was then added. In both types of assay, after washing away any unreacted conjugate, tetramethylbenzidine (substrate) was added, and colour developed in proportion to the amount of the particular cytokine bound to the plate. Colour development was stopped by stop solutions and colorimetric determination was performed using a reader EASIA-reader (Medgenix Diagnostics). The concentrations of cytokines in the samples were determined by comparing the optical densities of the samples to those on standard curves. Results were expressed in pg.mL BAL fluid $^{-1}$. The sensitivity of the technique allowed the detection of levels as low as $1 \mathrm{pg} \cdot \mathrm{mL}^{-1}$ for IL- 8 and IL-10, 2 $\mathrm{pg} \cdot \mathrm{mL}^{-1}$ for IL- $1 \beta$, and $3 \mathrm{pg} \cdot \mathrm{mL}^{-1}$ for IL- 6 and TNF- $\alpha$.

The levels of cytokines were given as the concentration, in the BAL fluid because the instilled volume was always the same and no reference molecule (urea or albumin) compensating for the dilution of the lavaged fluid is valid [11].

\section{Microbiological evaluation}

Respiratory samples were Gram-stained and homogenized. Undiluted as well as diluted secretions were plated on blood, chocolate, Wilkens-Chalgren and Sabouraud agar. Identification of micro-organisms was performed according to standard methods [12]. Susceptibility testing was performed using the agar diffusion method. Results of quantitative cultures were expressed in colony-forming units (cfu).

Bacterial agents were classified into potentially pathogenic microorganisms (PPMs) or non-PPMs as described elsewhere [13]. In contrast to in pneumonia, there is no accepted standard of microbial quantification for defining colonization. In order to minimize the risk of dealing with contaminants, only pathogens with counts of $\geq 10^{2}$ $\mathrm{cfu} \cdot \mathrm{mL}^{-1}$ in PSB samples and $\geq 10^{3} \mathrm{cfu} \cdot \mathrm{mL}^{-1}$ in BALF were regarded as significant.

\section{Statistical analysis}

Data are presented as means \pm SEM unless stated otherwise. Continuous variables were compared using the nonparametric Mann-Whitney U-test and categorical variables using the Chi-squared test or Fisher's exact test, where appropriate. Unifactorial analysis of variance with post hoc Bonferroni correction was performed for multiple comparisons of continuous variables. Correlations were calculated using Spearman's rank test. All reported p-values are twotailed. The level of significance was set at $5 \%$.

\section{Results}

\section{Patients}

Seventy-eight patients were included in the study. Bronchoscopy was well tolerated by all patients without adverse effects. Patient characteristics are given in table 1.

\section{Number of samples retrieved}

Twelve controls (all smokers) and all COPD patients underwent quantitative culture of PSB samples, and quantitative cultures of BALF were performed in nine controls (all smokers) and in 24 patients with mild, eight with moderate and 11 severe with COPD. Differential cell counts in BALF were performed in all nonsmoking controls, 10 smoking controls and in 14 patients with mild, six with moderate and 10 with severe COPD. Cytokine patterns in BALF were determined in all nonsmoking controls, 10 smoking controls and in 13 patients with mild, seven with moderate and 10 with severe COPD.

\section{Total and differential cell counts in bronchoalveolar lavage fluid}

The recovery of BAL fluid was significantly greater in nonsmoking controls than in patients with COPD (mean \pm SD $64 \pm 21 \mathrm{~mL}$ BAL fluid in nonsmoking controls, $44 \pm 10$ $\mathrm{mL}$ in smoking controls, $35 \pm 21 \mathrm{~mL}$ in patients with mild COPD, $26 \pm 19 \mathrm{~mL}$ moderate COPD, and $21 \pm 11 \mathrm{~mL}$ severe COPD; $<<0.0001)$. There were no significant differences in cell viability and total cell counts in BAL fluid between the groups. However, there was a trend towards greater cellularity in smoking controls and COPD patients as compared to nonsmoking controls (table 2).

The mean total and differential cell counts are given in table 2 . There was a trend for the percentage of neutrophils to be higher in smoking controls and mild and moderate COPD patients as compared to nonsmoking

Table 2. - Cell viability and total and differential cell counts in bronchoalveolar lavage fluid from controls and chronic obstructive pulmonary disease (COPD) patients

\begin{tabular}{|c|c|c|c|c|c|}
\hline & \multicolumn{2}{|c|}{ Control } & \multicolumn{3}{|c|}{ COPD } \\
\hline & Nonsmoker & Smoker & Mild & Moderate & Severe \\
\hline Subjects $n$ & 8 & 10 & 14 & 6 & 10 \\
\hline Cell viability \% & $85.8 \pm 3.8$ & $77.5 \pm 6.1$ & $83.0 \pm 2.6$ & $87.7 \pm 1.5$ & $73.6 \pm 4.1$ \\
\hline Total cell count $10^{5}$ cells $\cdot \mathrm{mL}^{-1}$ & $2.1 \pm 0.5$ & $5.9 \pm 1.4$ & $13.3 \pm 4.2$ & $7.2 \pm 1.5$ & $6.6 \pm 1.9$ \\
\hline Macrophages \% & $87.1 \pm 2.1$ & $83.5 \pm 8.8$ & $77.4 \pm 5.8$ & $81.0 \pm 8.9$ & $65.1 \pm 9.3$ \\
\hline Neutrophils \% & $1.3 \pm 0.5$ & $11.4 \pm 8.8$ & $13.2 \pm 6.2$ & $11.7 \pm 6.2$ & $26.7 \pm 9.9$ \\
\hline Lymphocytes \% & $11.6 \pm 1.8$ & $5.0 \pm 1.6$ & $8.6 \pm 1.8$ & $4.5 \pm 1.4$ & $11.7 \pm 2.7$ \\
\hline Eosinophils \% & 0 & $0.1 \pm 0.1$ & $0.8 \pm 0.5$ & $2.5 \pm 1.9$ & $0.3 \pm 0.3$ \\
\hline Macrophages $10^{5}$ cells $\cdot \mathrm{mL}^{-1}$ & $1.8 \pm 0.47$ & $5.1 \pm 1.4$ & $10.8 \pm 3.7$ & $5.6 \pm 1.4$ & $2.8 \pm 0.6$ \\
\hline Neutrophils $10^{5}$ cells $\cdot \mathrm{mL}^{-1}$ & $0.03 \pm 0.01$ & $0.55 \pm 0.44$ & $1.52 \pm 1.8$ & $0.95 \pm 0.6$ & $3.3 \pm 1.8$ \\
\hline Lymphocytes $10^{5}$ cells $\cdot \mathrm{mL}^{-1}$ & $0.24 \pm 0.07$ & $0.36 \pm 0.18$ & $0.89 \pm 0.26$ & $0.39 \pm 0.14$ & $0.78 \pm 0.32$ \\
\hline Eosinophils $10^{5}$ cells $\cdot \mathrm{mL}^{-1}$ & 0 & $0.01 \pm 0.01$ & $0.03 \pm 0.02$ & $0.24 \pm 0.19$ & $0.03 \pm 0.03$ \\
\hline
\end{tabular}

Data are presented as mean \pm SD. No differences were statistically significant. 

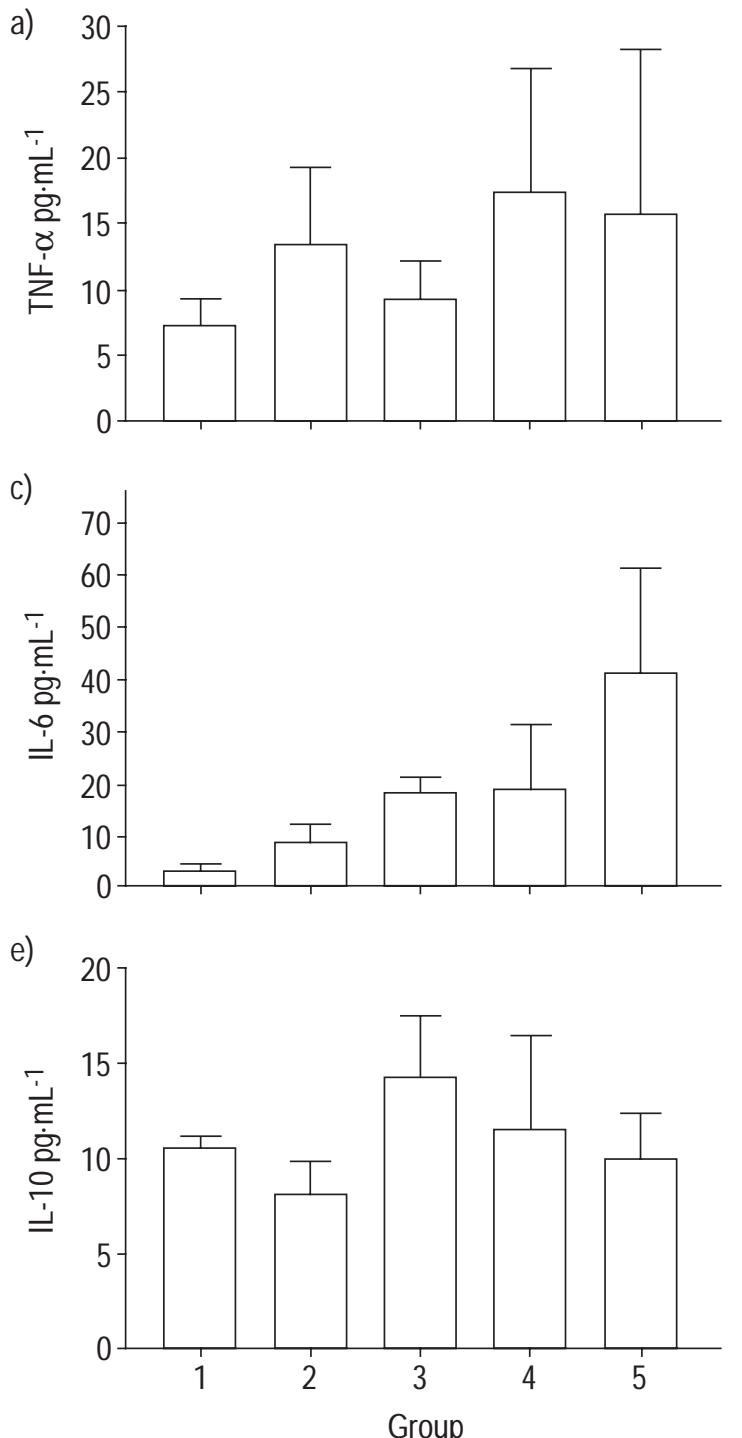
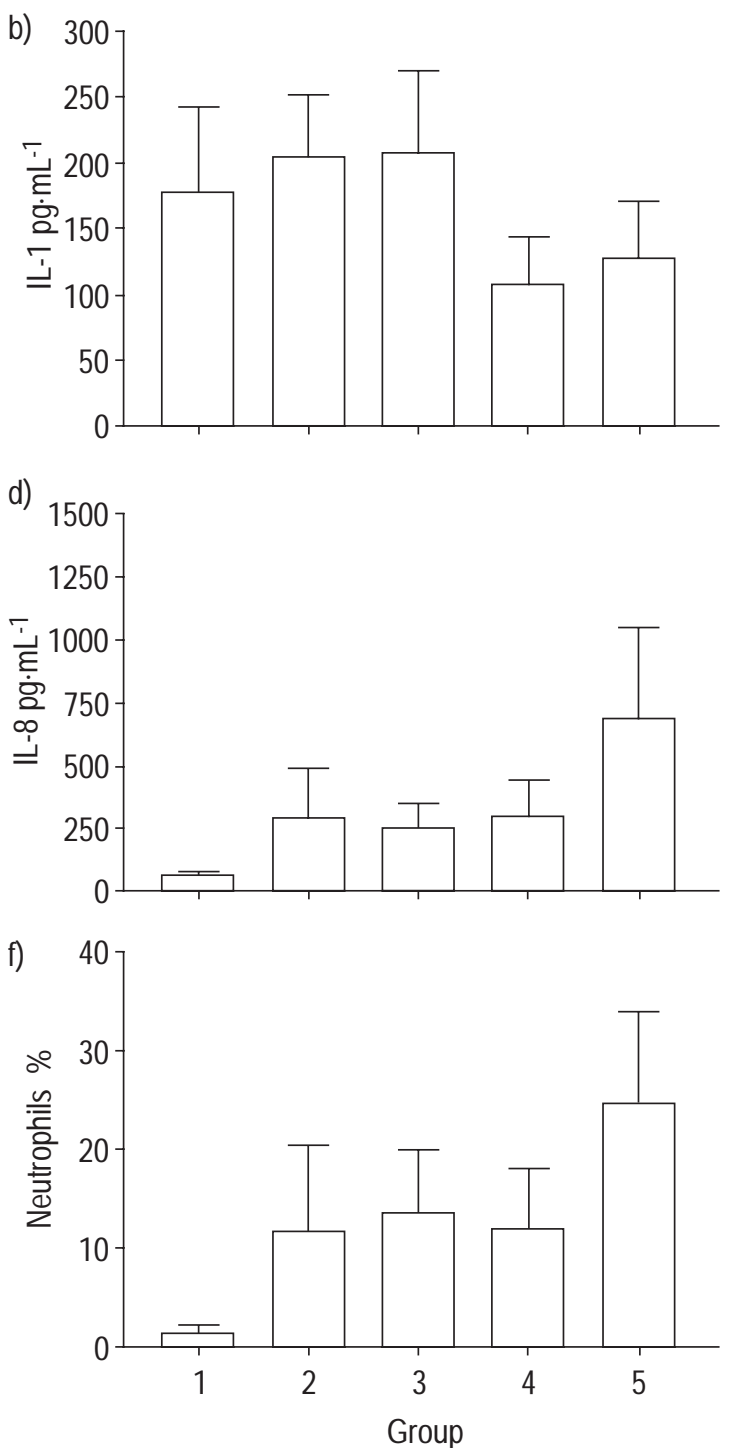

Fig. 1. - Cytokine levels and neutrophil counts in bronchoalveolar lavage fluid (BALF): a) tumour necrosis factor- $\alpha$ (TNF- $\alpha$ ); b) interleukin (IL)-1; c) IL-6; d) IL-8; e) IL-10; and f) neutrophils. 1: nonsmoking controls; 2: smoking controls; 3: mild chronic obstructive pulmonary disease (COPD) patients, 4: moderate COPD patients; 5: severe COPD patient.

controls and to be highest in severe COPD patients (fig. 1). As regards absolute cell counts, there were no differences between smoking controls and COPD patients in regard neutrophils and eosinophils, but a trend to increased macrophage and lymphocyte counts in smoking controls and COPD patients.

\section{Cytokine profiles}

The mean cytokine concentrations are given in table 3 . There was a trend for TNF- $\alpha$ to be higher in smoking controls and COPD patients as compared to controls. Mean IL-6 levels increased virtually linearly from nonsmoking controls through smoking controls and mild and moderate COPD to severe COPD. A similar trend was observed for mean IL-8 levels. Conversely, mean IL- $1 \beta$ levels were lowest in moderate and severe COPD patients. IL-10 levels did not reveal any trend (fig. 1).

As regards COPD patients, cytokine levels were not significantly different between current smokers and exsmo- kers, although there was a trend towards TNF- $\alpha$ IL- 8 being higher in current smokers $(19.1 \pm 12.4$ versus $10.3 \pm 3.6, \mathrm{p}=$ 0.055 and $571.1 \pm 380.8$ versus $319.6 \pm 71.2, \mathrm{p}=0.059$ ).

Correlations between forced expiratory volume in one second and cytological cell counts and cytokines levels

FEV1 \% pred was significantly inversely correlated with pack-yrs of cigarette smoking $(\rho=-0.47, p<0.0001)$, the percentage of neutrophils $(\rho=-0.56, p<0.0001)$ IL-6 $(\rho=$ $-0.37, p=0.01)$ and IL- 8 concentration $(\rho=-0.43, p=0.004)$ in BAL fluid, but not TNF- $\alpha$ (fig. 2).

Correlations between percentage of neutrophils in bronchoalveolar lavage fluid and cytokine levels

Significant correlations could be found for the percentage of neutrophils in BAL fluid and pack-yrs of cigarette smoking $(\rho=0.39, p=0.01)$ and IL-8 $(\rho=0.69, p<00001)$, and TNF- $\alpha$ concentration $(\rho=0.4, p<0.005)$ (fig. 2 ). 
Table 3. - Bronchoalveolar lavage fluid cytokine patterns in chronic obstructive pulmonary disease (COPD) patients and controls

\begin{tabular}{|c|c|c|c|c|c|}
\hline & \multicolumn{2}{|c|}{ Control } & \multicolumn{3}{|c|}{ COPD } \\
\hline & Nonsmoker & Smoker & Mild & Moderate & Severe \\
\hline Subjects n & 8 & 9 & 13 & 7 & 10 \\
\hline $\mathrm{IL}-1 \beta \mathrm{pg} \cdot \mathrm{mL}^{-1}$ & $177 \pm 66.0$ & $205.1 \pm 48.1$ & $208.8 \pm 61.5$ & $105.9 \pm 36.9$ & $127.3 \pm 45.3$ \\
\hline IL-6 pg.mL $\mathrm{mL}^{-1}$ & $3.4 \pm 1.1$ & $8.4 \pm 2.9$ & $17.6 \pm 3.0$ & $18.3 \pm 12.2$ & $40.4 \pm 20.7$ \\
\hline IL- $8 \mathrm{pg} \cdot \mathrm{mL}^{-1}$ & $48.8 \pm 14.4$ & $287.0 \pm 198.6$ & $255.2 \pm 83.7$ & $292.6 \pm 131.7$ & $673.8 \pm 372.2$ \\
\hline $\mathrm{IL}-10 \mathrm{pg} \cdot \mathrm{mL}^{-1}$ & $10.4 \pm 0.6$ & $8.0 \pm 1.6$ & $14.1 \pm 3.1$ & $11.3 \pm 4.9$ & $9.7 \pm 2.5$ \\
\hline TNF- $\alpha \mathrm{pg} \cdot \mathrm{mL}^{-1}$ & $7.1 \pm 2.2$ & $12.1 \pm 5.8$ & $9.1 \pm 3.1$ & $17.3 \pm 9.3$ & $15.7 \pm 12.4$ \\
\hline
\end{tabular}

Data are presented as mean \pm SD. IL: interleukin; TNF- $\alpha$ : tumour necrosis factor- $\alpha$. No differences were statistically significant.

\section{Microbiological results}

The PSB technique revealed significant amounts of PPMs in 22 of 64 (34\%) patients, and BAL in 14 of 52 $(27 \%)$ (Ns). The kappa coefficient for qualitative agreement on PPMs was $0.39(\mathrm{p}=0.002)$ and for quantitative agreement $0.39(\mathrm{p}=0.0009)$.

Culture results revealed that five of 12 (42\%) smoking controls, and nine of 28 (32\%) COPD patients with mild, six of $11(55 \%)$ with moderate and two of $13(15 \%)$ with severe airflow limitation had PPMs above the thresholds in PSB samples or BALF (NS for all comparisons). Overall colonization rates were $42 \%$ in smoking controls versus $33 \%$ in all COPD patients (NS). The corresponding numbers for non-PPMs above the thresholds were seven of 12 $(58 \%)$ in smoking controls, and 20 of $28(71 \%)$ in COPD patients with mild, three of $11(27 \%)$ with moderate, and five of $13(39 \%)$ with severe airflow limitation. Overall col-
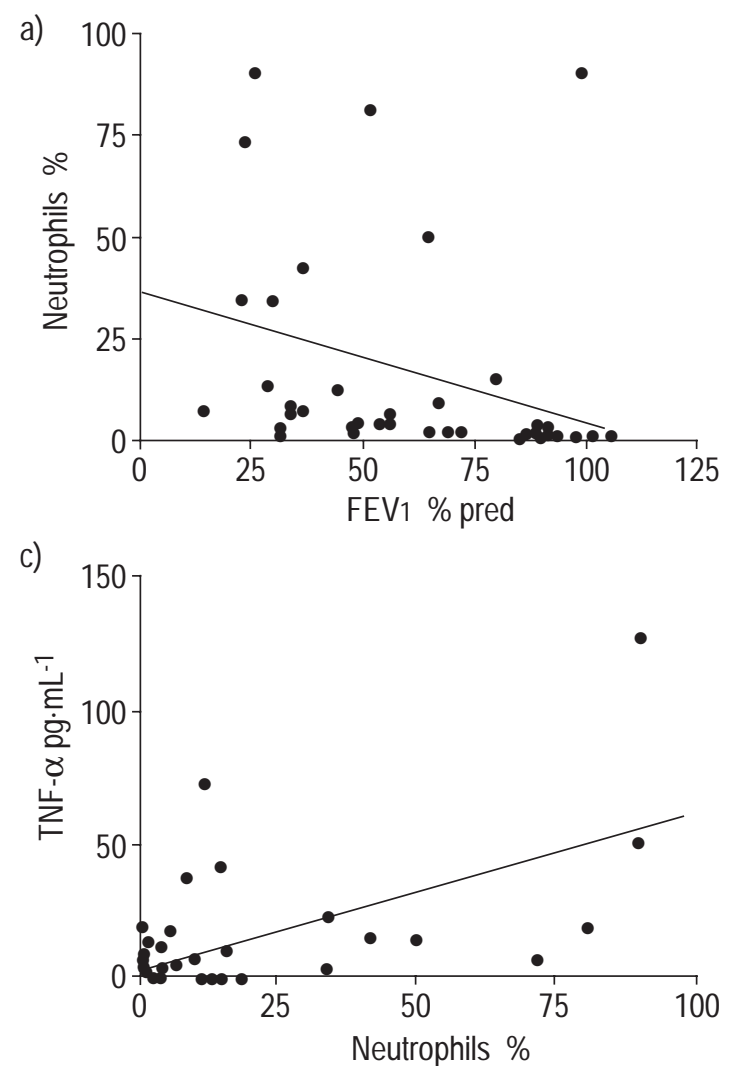

Fig. 2. - Correlations between forced expiratory volume in one second (FEV1) and inflammatory markers (a) neutrophils (r=-0.56, p<0.0001); and b) interleukin-8 (IL-8) $(\mathrm{r}=-0.43, \mathrm{p}=0.004)$ and between $(\mathrm{c})$ tumour necrosis factor- $\alpha(\mathrm{TNF}-\alpha)(\mathrm{r}=0.4, \mathrm{p}<0.005)$; and inflammatory markers and $\mathrm{d}) \mathrm{IL}-8$ $(\mathrm{r}=0.69, \mathrm{p}<0.0001)$ in bronchoalveolar lavage fluid. onization rates were $58 \%$ in smoking controls versus $54 \%$ in all COPD patients (Ns).

Table 4 provides an overview of the micro-organisms retrieved. As regards PPMs, the majority were communityacquired pathogens (24 of $27,89 \%$ ), whereas only two were Gram-negative enteric bacilli (GNEB) and one Stenotrophomonas maltophilia. Colonization patterns were not affected by the severity of airflow obstruction. Within the non-PPM group, Streptococcus viridans was the microorganism most frequently encountered.

Associations between cytological cell counts, cytokines and microbial patterns

The presence of PPMs in significant amounts was significantly associated with higher neutrophil counts as compared to PPMs in nonsignificant amounts $(33.2 \pm 10.4$ versus

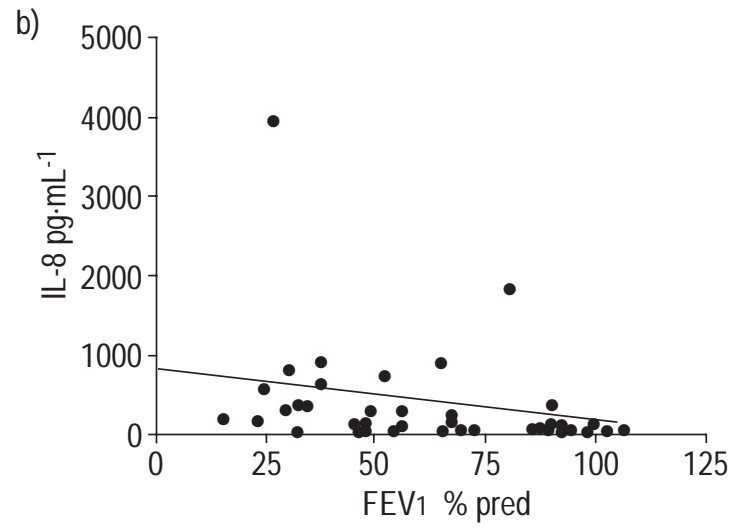

d)

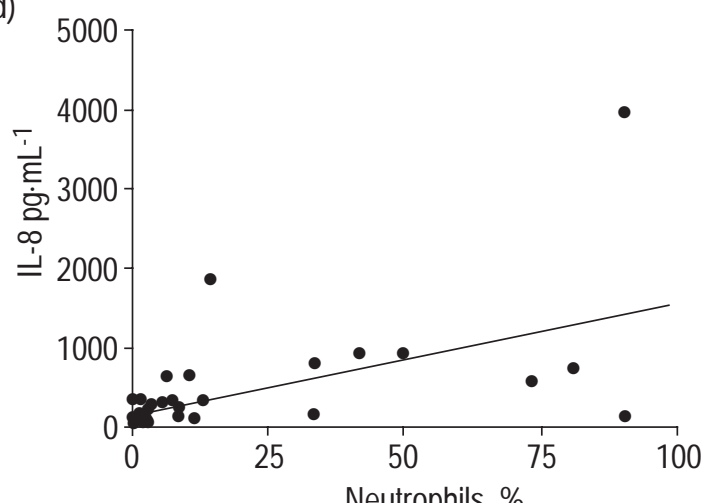


Table 4. - Microbial patterns of controls and chronic obstructive pulmonary disease (COPD) patients

\begin{tabular}{|c|c|c|c|c|c|c|c|c|}
\hline \multirow{3}{*}{ Micro-organism } & & & \multicolumn{6}{|c|}{ COPD } \\
\hline & \multicolumn{2}{|c|}{ Control smokers } & \multicolumn{2}{|c|}{ Mild } & \multicolumn{2}{|c|}{ Moderate } & \multicolumn{2}{|c|}{ Severe } \\
\hline & $<\mathrm{CO}$ & $\geq \mathrm{CO}$ & $<\mathrm{CO}$ & $\geq \mathrm{CO}$ & $<\mathrm{CO}$ & $\geq \mathrm{CO}$ & $<\mathrm{CO}$ & $\geq \mathrm{CO}$ \\
\hline Subjects n & \multicolumn{2}{|c|}{12} & \multicolumn{2}{|c|}{28} & \multicolumn{2}{|c|}{11} & \multicolumn{2}{|c|}{13} \\
\hline $\begin{array}{l}\text { PPIMS } \\
\text { Community-acauired } *\end{array}$ & & & & 10 & & & & \\
\hline GNEB + and $P$. aeruginosa/S. maltophilia & 0 & $\begin{array}{l}0 \\
0\end{array}$ & $\begin{array}{l}2 \\
1\end{array}$ & $\begin{array}{r}10 \\
0\end{array}$ & $\begin{array}{l}0 \\
0\end{array}$ & $\begin{array}{l}5 \\
2\end{array}$ & $\begin{array}{l}2 \\
0\end{array}$ & $\begin{array}{l}3 \\
1\end{array}$ \\
\hline Non-PPMs & 2 & 8 & 8 & 30 & 1 & 4 & 6 & 11 \\
\hline
\end{tabular}

*: Streptococcus pneumoniae, Staphylococcus aureus, Haemophilus influenzae and Moraxella catarrhalis; ${ }^{+}$: Escherichia coli and Protesu mirabilis. CO: cut-off $\left(\geq 10^{2}\right.$ colony-forming units $(\mathrm{cfu}) \cdot \mathrm{mL}^{-1}$ in protected specimen brush samples and $\geq 10^{3} \mathrm{cfu} \cdot \mathrm{mL}^{-1}$ in bronchoalveolar lavage fluid; P. aeruginosa: Pseudomonas aeruginosa; S. maltophilia: Stenotrophomonas maltophilia.

$10.1 \pm 3.5 \%, \mathrm{p}=0.02)$ as well as higher TNF- $\alpha$ levels $(29.9 \pm$ 10.8 versus $\left.6.3 \pm 2.1 \mathrm{pg} \cdot \mathrm{mL}^{-1}, \mathrm{p}=0.01\right)$. A nonsignificant trend was also obvious for IL-8 levels $(658.9 \pm 312.6$ versus 311.2 $\pm 93.9 \mathrm{pg} \cdot \mathrm{mL}^{-1}, \mathrm{p}=0.21$ ) (fig. 3).

No corresponding associations could be established for the presence of non-PPMs in significant amounts.

\section{Discussion}

This study yields three main findings. 1) FEV1 (\% pred) was inversely correlated with pack-yrs of cigarette smoking and the percentage of neutrophils and IL-6 and IL-8 concentration in BAL fluid. Accordingly, pack-yrs of cigarette smoking and IL- 8 and TNF- $\alpha$ concentration were positively correlated with the percentage of neutrophils in BAL fluid. 2) Smoking controls and COPD patients were frequently colonized by PPMs in the bronchial tree (33\%), mainly by community endogenous pathogens. Colonization rates and patterns of PPMs were not affected by severity of airflow obstruction. 3) However, the presence of significant amounts of PPMs was significantly associated with higher percentages of neutrophils and TNF- $\alpha$ concentration in BAL fluid.

The present study confirms previous findings, from studies using BAL fluid $[14,15]$ and induced sputum [16], that, in contrast to in asthma, airway inflammation in patients with COPD is characterized mainly by a neutrophilic pattern. However, previous studies using BAL fluid excluded patients with severe COPD for safety reasons [14-16]. These patients were only included in one study using sputum induction [17]. It was decided to include patients with all degrees of airflow limitation in the present study. A clear trend for the percentage of neutrophils to be higher in smoking controls and mild and moderate COPD patients as compared to nonsmoking controls and to be highest in severe COPD patients was found. Airflow limitation was correlated to pack-yrs of cigarette smoking as well as the percentage of neutrophils in BAL fluid, corroborating previous findings of others [14-16]. In accordance with this, increased activity of bronchial neutrophils, as evidenced by increased levels of myeloperoxidase in patients with COPD, has also been described $[16,18]$.

A corresponding inverse correlation was found with airflow limitation (FEV1 as \% pred) and IL-6 as well as IL-8 concentration. IL-6 is an airway epithelial cell and a macrophage product that exerts pleiotropic pro-inflammatory effects. Thus, it may represent an additional marker of bronchial mucosal inflammation in BAL fluid [19]. Conversely, IL-8 is the main mediator of neutrophil chemotaxis [19]. Similar increasing levels of IL- 6 and IL- 8 were observed, as with the percentage of neutrophils, dependent on smoking status and the degree of airflow limitation. Increased IL-8 levels in COPD patients were also found by others, using both induced sputum [17] and bronchoalveolar lavage [18]. Conversely, to the authors' knowledge, IL-6 has not been investigated so far in this population. Since IL-8 was correlated with the percentage of neutrophils in BAL fluid, it may mainly reflect neutrophil recruitment [20]. This is also true for TNF- $\alpha$, which also correlated with the percentage of neutrophils in BAL fluid and which has been shown to increase IL-8 production from
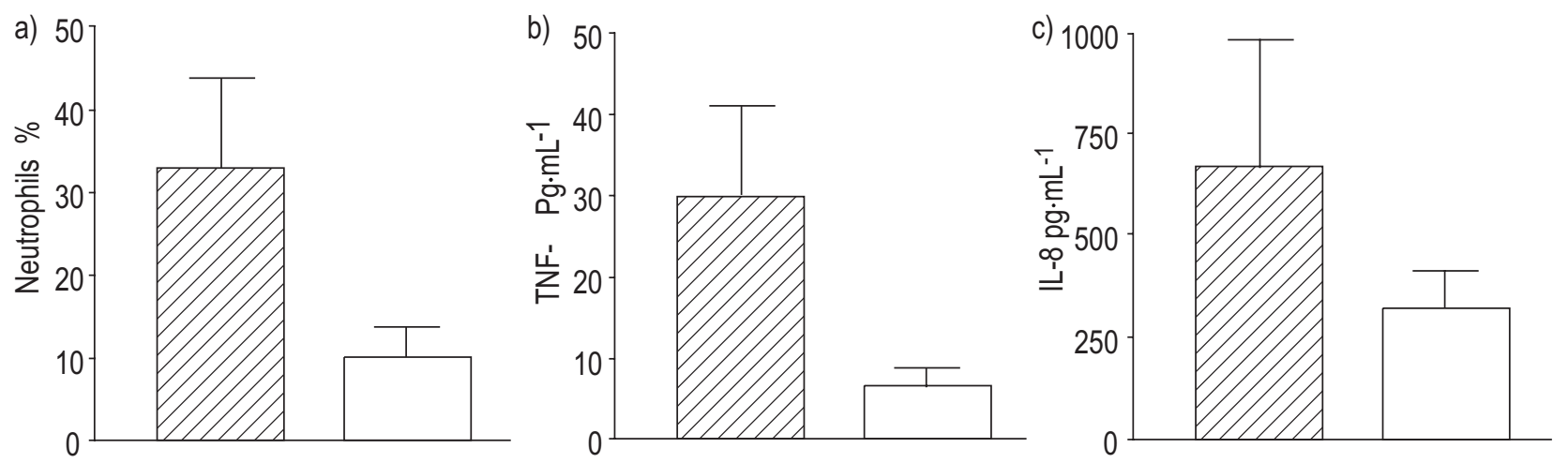

Fig. 3. - Percentage of neutrophils $(\mathrm{a}, \mathrm{p}=0.02)$ and concentrations of tumour necrosis factor- $\alpha(\mathrm{TNF}-\alpha)(\mathrm{b}, \mathrm{p}=0.01)$ and interleukin- 8 (IL- 8$)(\mathrm{c}, \mathrm{p}=0.21)$ in bronchoalveolar lavage fluid from patients with $(\mathbb{\complement})$ and without $(\square)$ potentially pathogenic micro-organisms in culture. 
epithelial cells and neutrophils $[21,22]$. Finally, IL-1 $\beta$ and IL-10 concentrations seemed to be lowest in patients with severe COPD, reflecting upregulation of the inflammatory response [22].

When interpreting colonization rates of COPD patients, it should be realized that these may vary at different times of year or during the course of COPD. Moreover, sampling errors must be taken into account. Nevertheless, keeping in mind these potential limitations, the colonization rates of the bronchial tree obtained were comparable with recent observations of others $[4,23]$. PPMs were detected in $42 \%$ of smoking controls and $33 \%$ of COPD patients, mostly corresponding to community endogenous pathogens. RIISE et al. [18] found an overall colonization rate of $37 \%$ in smokers with nonobstructive chronic bronchitis as compared to $33 \%$ in patients with COPD. The proportions were 11 and $22 \%$, respectively, when only PPMs were taken into account [18]. Monsó et al. [23] found a colonization rate with PPMs in stable patients with COPD of $25 \%$. A similar low proportion of GNEB and Pseudomonas spp. was found ( $11 \%$ in the present study versus $5 \%$ in that of Monsó et al. [23]). As regards non-PPMs, these micro-organisms were found in $58 \%$ of smoking controls and $54 \%$ of COPD patients, with $S$. viridans the most frequently encountered species. Obviously, smoking and not airflow limitation was the main factor determining airway colonization, corroborating previous findings of others [2]. By the same token, no relationship of the severity of airflow limitation could be demonstrated with either colonization rates or type of PPMs. Likewise, in a recent study of COPD patients with severe exacerbations requiring mechanical ventilation, no association of type of PPMs with severity of airflow limitation could be demonstrated [24]. These observations suggest that there is a general the disposition to colonization with PPMs in the presence of airway inflammation.

Conversely, the presence of PPMs was significantly associated with increased percentages of neutrophils and levels of TNF- $\alpha$. A corresponding trend was obvious for increased IL-8 levels. Others have found that some Grampositive (e.g. Streptococcus pneumoniae) and Gramnegative bacteria stimulate TNF- $\alpha$ production by macrophages [25]. Thus, the present study provides evidence for bronchial colonization with PPMs (and not only infection) being harmful by further enhancing airway inflammation. If these findings could be confirmed in further investigations, there would be a potential role for the prophylactic antimicrobial treatment of patients with COPD and proven bronchial colonization with PPMs. Corresponding reductions in IL-1 and TNF- $\alpha$ concentration in the sputum of patients with bronchiectasis after a clinical response to antimicrobial treatment have been recently demonstrated [26]. Conversely, there was no evidence for a comparable role of non-PPMs as promoters of bronchial inflammation.

A general methodological problem of BAL studies is the lack of an accepted reference to compensate for the dilution of lavaged fluid. In the present study, decreasing recovery of BAL fluid with increasing severity of COPD might have influenced the results of cytokine measurements. However, it seems that a decreased recovery should lead to an underestimation of cytokine concentrations, since endothelial lining fluid sampling might have been rendered incomplete. Therefore, it is thought that differences in recovery are not likely to result in type-1 errors as regards the association of cytokine levels with pulmonary function and colonization. Another concern may be that cytokine levels in COPD patients may have been affected by current smoking. However, the differences in cytokine level were nonsignificant. For this reason, the increased TNF- $\alpha$ and IL-8 levels in current smokers might have impeded even more striking differences between COPD groups. Finally, inhaled steroid treatment may influence the cytological and cytokine patterns. However, there were no significant differences in any parameter when calculations were repeated in subgroups receiving or not receiving inhaled steroids (data not shown). Instead, there was a uniform trend towards higher percentages of neutrophils and levels of cytokines in COPD patients inhaling steroids, indicating that inhaled steroids were prescribed to patients with higher inflammatory activity. Thus, it cannot be excluded that differences in COPD patients as compared to controls would have been more pronounced in the absence of inhaled steroid treatment.

In conclusion, the present study confirms bronchial neutrophilia as a key inflammatory pattern in chronic obstructive pulmonary disease patients which may predispose to bronchial bacterial colonization. Moreover, it provides evidence that bronchial colonization with potentially pathogenic micro-organisms represents an independent stimulus for additional airway inflammation.

\section{References}

1. Marcy TW, Merrill WW. Cigarette smoking and respiratory tract infection. Clin Chest Med 1987; 8: 381-391.

2. Irwin RS, Erickson AD, Pratter MR, et al. Prediction of tracheobronchial colonization in current cigarette smokers with chronic obstructive bronchitis. J Infect Dis 1982; 145: 234-241.

3. Haas H, Morris JF, Samson S, Kilbourn JP, Kim PJ. Bacterial flora of the respiratory tract in chronic bronchitis: comparison of transtracheal, fiberbronchoscopic and oropharyngeal sampling methods. Am Rev Respir Dis 1977; 116: 41-47.

4. Riise GC, Larsson S, Larrson P, Jeansson S, Andersson BA. The intrabronchial microbial flora in chronic bronchitis patients: a traget for $N$-acetylcysteine therapy? Eur Respir J 1994; 7: 94-101.

5. Murphy TF, Sethi S. Bacterial infection and chronic obstructive pulmonary disease. Am Rev Respir Dis 1992; 146: $1067-1083$.

6. Kanner RE, Renzetti AD Jr, Klauber MR, Smith CB, Golden CA. Variables associated with changes in spirometry in patients with obstructive lung diseases. Am J Med 1979; 67: 44-50.

7. Cole P. Host microbe relationships in chronic respiratory infection. Respiration 1989; 55: 5-8.

8. Wilson R. The pathogenesis and management of bronchial infections: the vicious circle of respiratory decline. Rev Contemp Pharmacother 1992; 3: 103-112.

9. American Thoracic Society. Standards for the diagnosis and care of patients with chronic obstructive pulmonary disease. Am J Respir Crit Care Med 1995; 152: S78-S83.

10. Monton C, Torres A, El-Ebiary M, Fillela X, Xaubet A, Puig de la Bellacasa J. Cytokine expression in severe pneumonia: a bronchoalveolar lavage study. Crit Care Med 1998; (in press). 
11. Walters EH, Gardiner PV. Bronchoalveolar lavage as a research tool. Thorax 1991; 46: 613-618.

12. Balows A, Harsier WJ Jr. Manual of clinical microbiology. 5th edition, section III. Washington DC: American Society of Microbiology. 1991; pp. 209-553.

13. Cabello H, Torres A, Celis R, et al. Distal airway bacterial colonisation in healthy subjects and chronic lung diseases: a bronchoscopic study. Eur Respir J 1997; 10: 11371144.

14. Martin TR, Raghu G, Maunder RJ, Springmeyer S. The effects of chronic bronchitis and chronic airflow obstruction on lung cell populations recovered by bronchoalveolar lavage. Am Rev Respir Dis 1985; 132: 254-260.

15. Thompson AB, Daughton D, Robbins RA, Ghafouri MA, Oehlerking M, Rennard SI. Intraluminal airway inflammation in chronic bronchitis. Characterization and correlation with clinical parameters. Am Rev Respir Dis 1989; 140: 1527-1537.

16. Linden M, Rasmussen JB, Pitulainen E, et al. Airway inflammation in smokers with nonobstructive and obstructive chronic bronchitis. Am Rev Respir Dis 1993; 148: $1226-1232$.

17. Keatings VM, Collins PD, Scott DM, Barnes PJ. Differences in interleukin- 8 and tumor necrosis factor in induced sputum from patients with chronic obstructive pulmonary disease or asthma. Am J Respir Crit Care Med 1996; 153: 530-534.

18. Riise GC, Ahlstedt S, Larsson S, et al. Bronchial inflammation in chronic bronchitis assessed by measurement of cell products in bronchial lavage fluid. Thorax 1995; 50: 360-365.
19. Levine SJ. Bronchial epithelial cell-cytokine interactions in airway inflammation. J Investig Med 1995; 43: 241249.

20. Richman-Eisenstadt JBY, Jorens PG, Hebert CA, Ueki I, Nadel JA. Interleukin-8: an important chemoattractant in sputum of patients with chronic inflammatory airway diseases. Am J Physiol 1993; 264: L413-L418.

21. Kwon OJ, Au BT, Collins PD, et al. Tumor necrosis factor-induced IL-8 expression in cultured human airway epithelial cells. Am J Physiol 1994; 267: L398-L405.

22. Cassatella MA, Meda L, Bonora S, Ceska M, Constantin G. IL-10 inhibits the release of proinflammatory cytokines from human polymorphoneclear phagocytes. Evidence for an autocrine role of tumor necrosis factor and IL- $1 \beta$ in mediating the production of IL- 8 triggered by lipopolysaccaride. J Exp Med 1993; 178: 2207-2211.

23. Monsó E, Ruiz J, Rosell A, et al. Bacterial infection in chronic obstructive pulmonary disease. A study of stable and exacerbated outpatients using the protected specimen brush. Am J Respir Crit Care Med 1995; 152: 1316-1320.

24. Soler N, Torres A, Ewig S, et al. Bronchial microbial patterns in severe exacerbations of chronic obstructive pulmonary disease (COPD) requiring mechanical ventilation. Am J Respir Crit Care Med 1998; 157: 1498-1505.

25. Simpson SQ, Singh R, Bice DE. Heat-killed pneumococci and pneumococcal capsular polysaccarides stimulate tumour necrosis factor- production by murine macrophages. Am J Respir Cell Mol Biol 1994; 10: 284-289.

26. Eller J, Lapa e Silva JR, Poulter LW, Lode H, Cole PJ. Cells and cytokines in chronic bronchial infection. Ann NY Acad Sci 1994; 725: 331-345. 